\title{
Thyroid hormone action in mitochondria
}

\section{Wrutniak-Cabello, F Casas and G Cabello}

\author{
UMR Différenciation Cellulaire et Croissance (INRA, Université Montpellier II, ENSAM), \\ Unité d'Endocrinologie Cellulaire, INRA, 2 Place Viala, 34060 Montpellier Cedex 1, France
}

(Requests for offprints should be addressed to G Cabello; Email: cabello@ensam.inra.fr)

\begin{abstract}
Triiodothyronine (T3) is considered a major regulator of mitochondrial activity. In this review, we show evidence of the existence of a direct T3 mitochondrial pathway, and try to clarify the respective importance of the nuclear and mitochondrial pathways for organelle activity. Numerous studies have reported short-term and delayed T3 stimulation of mitochondrial oxygen consumption. Convincing data indicate that an early influence occurs through an extra-nuclear mechanism insensitive to inhibitors of protein synthesis. Although it has been shown that diiodothyronines could actually be T3 mediators of this short-term influence, the detection of specific T3-binding sites, probably corresponding to a $28 \mathrm{kDa}$ c-Erb A $\alpha 1$ protein of the inner membrane, also supports a direct $\mathrm{T} 3$ influence. The more delayed influence of thyroid hormone upon mitochondrial respiration probably results from mechanisms elicited at the nuclear level, including changes in phospholipid turnover and stimulation of uncoupling protein expression, leading to an increased inner membrane proton leak. However, the involvement of a direct mitochondrial T3 pathway leading to a rapid stimulation of mitochondrial protein synthesis has to be considered.
\end{abstract}

Both pathways are obviously involved in the T3 stimulation of mitochondrial genome transcription. First, a $43 \mathrm{kDa} \mathrm{c}-\mathrm{Erb} \mathrm{A} \alpha 1$ protein located in the mitochondrial matrix ( $\mathrm{p} 43$ ), acting as a potent T3-dependent transcription factor of the mitochondrial genome, induces early stimulation of organelle transcription. In addition, T3 increases mitochondrial TFA expression, a mitochondrial transcription factor encoded by a nuclear gene. Similarly, the stimulation of mitochondriogenesis by thyroid hormone probably involves both pathways. In particular, the c-erb $\mathrm{A} \alpha$ gene simultaneously encodes a nuclear and a mitochondrial T3 receptor (p43), thus ensuring coordination of the expression of the mitochondrial genome and of nuclear genes encoding mitochondrial proteins.

Recent studies concerning the physiological importance of the direct mitochondrial T3 pathway involving p43 led to the conclusion that it is not only involved in the regulation of fuel metabolism, but also in the regulation of cell differentiation. As the processes leading to or resulting from differentiation are energy-consuming, p43 coordination of metabolism and differentiation could be of significant importance in the regulation of development. Fournal of Molecular Endocrinology (2001) 26, 67-77

\section{INTRODUCTION}

It is generally assumed that the fundamental influence of thyroid hormone occurs through the control of gene transcription, mediated by several triiodothyronine (T3)-binding transcription factors belonging to the nuclear receptor superfamily. Two genes encoding these receptors have been character- ized, c-erb $A \alpha$ and c-erb $A \beta$. In rats, mice and men, due to alternative splicing processes, the c-erb A $\alpha$ gene encodes three proteins $\alpha 1, \alpha 2$ and $\alpha 3$; only the first binds T3 and stimulates gene transcription in response to the hormone. Shorter forms of $\alpha$-receptors have also been characterized (Chassande et al. 1997) in mice. In the same species, the c-erb $\mathrm{A} \beta$ gene encodes two receptors, $\beta 1$ and $\beta 2$, differing 
in their pattern of tissue expression; whereas c-Erb $A \beta 1$ is expressed in a wide range of tissues, c-Erb $\mathrm{A} \beta 2$ is found almost exclusively in the pituitary where it inhibits thyrotrophin (TSH) $\alpha$ - and $\beta$-subunit gene transcription (Abel et al. 1999) by binding to negative T3 response elements (REs) present on these genes (Burnside et al. 1989, Bodenner et al. 1991). Gene knock-out studies in mice have confirmed the specific involvement of the c-erb A $\beta$ gene in T3 negative feedback on TSH synthesis (Forrest et al. 1996, Abel et al. 1999, Gauthier et al. 1999).

Despite spectacular progress in the knowledge of the T3 nuclear pathway over the last 14 years, a clear answer to a recurrent question is still lacking. The major involvement of thyroid hormone in the regulation of development, growth and metabolism suggests that it controls a variety of complex pathways. Through its c-Erb A receptors regulating directly or indirectly the expression of numerous genes, this unique mechanism could enable T3 to induce a broad spectrum of activities. However, is it possible to rule out the implication of other mechanisms initiated outside the cell nucleus? The pertinence of this question is emphasized by convincing reports demonstrating that iodothyronines affect calcium signalling within minutes, independently of new protein synthesis (Davis et al. 1989, Segal 1989), and by the observation that, in vivo, thyroid hormone influences thermogenesis and the lipolytic activity of catecholamines, in less than $30 \mathrm{~min}$ (Andrews et al. 1979, Lynch et al. 1985, Wrutniak \& Cabello 1986). These last data substantiate the occurrence of non-genomic T3 pathways.

In this respect, mitochondria have a particular status in the cell. According to their postulated origin as a bacterium engulfed by the cell, they possess their own genome, a specific genetic code, and a specific apparatus involved in DNA replication, expression and protein synthesis. Despite this, the majority of mitochondrial proteins, including carriers, enzymatic subunits, transcription factors, DNA and RNA polymerases, or proteins involved in RNA translation, are encoded by nuclear genes and imported into mitochondria. Besides this nuclear contribution, the mitochondrial genome encodes 13 enzymatic subunits of the respiratory chain, two rRNAs and 22 tRNAs. Although the organelle's contribution to the synthesis of its own proteins appears to be quantitatively modest, it is an absolute requisite for life, as is clearly demonstrated by the extreme severity of diseases induced by rearrangements of the mitochondrial genome. Moreover, T3 is considered as a major regulator of mitochondrial biogenesis (Mutvei et al. 1989a), suggesting that the hormone acts on both nuclear genes and mitochondrial genome expression. In fact, it appears now that nuclear and direct mitochondrial pathways mediate this influence. In this review we have tried to define the respective contribution of each pathway in several well-established T3 influences on the organelle: stimulation of oxygen consumption, mitochondrial genome expression and mitochondriogenesis.

\section{THYROID HORMONE INFLUENCE ON MITOCHONDRIAL OXYGEN CONSUMPTION}

It has long been known that thyroid hormone administration increases oxygen consumption and heat production, and that, conversely, hypothyroidism has the opposite effects. Mitochondria extracted from the livers of hyperthyroid rats display oxygen consumption rates greater than those recorded in controls, whereas mitochondria from hypothyroid animals have a lower oxygen consumption (Brand \& Murphy 1987, Hoch 1988). Similar changes have been observed in hepatocytes isolated from hyperthyroid or hypothyroid animals (Nobes et al. 1990). Interestingly, two kinds of thyroid hormone action have been reported: a short-term influence occurring within minutes of thyroid hormone treatment, and a more delayed influence recorded after a few hours.

\section{Short-term influence}

Several studies have reported that $\mathrm{T} 3$ injection in hypothyroid rats increases oxygen consumption and oxidative phosphorylations measured in isolated liver mitochondria collected less than $30 \mathrm{~min}$ after hormone administration (PalaciosRomero \& Mowbray 1979, Sterling et al. 1980). In addition, this effect was not abrogated by protein synthesis inhibitors (Sterling et al. 1980). In vitro experiments also demonstrated that adding $\mathrm{T} 3$ to the incubation medium of isolated mitochondria from hypothyroid animals induced a similar influence within $2 \mathrm{~min}$ of the hormone being present (Sterling et al. 1977, Thomas et al. 1987). Moreover, Sterling \& Brenner (1995) reported a stimulation of the mitochondrial carrier adenine nucleotide translocase (ANT) displaying the same features. Rapidity, refractoriness to inhibitors of protein synthesis, and occurrence in the absence of nuclei ruled out the involvement of the T3 genomic pathway. Parallel to this, several studies have demonstrated that the mitochondrion is a major 
compartment of T3 accumulation in the cell (Palacios-Romero \& Mowbray 1979, Sterling et al. 1984b, Hashizume et al. 1986, Morel et al. 1996). These data led to the proposition that ANT was a major T3 target involved in the short-term influence of the hormone on the organelle. In agreement with this hypothesis, Sterling (1986) reported that ANT is a high-affinity binding site for T3. However, despite the availability of the purified protein and related antibodies or expression vectors, this last result has not received any confirmation. In particular, as were others, we were unable to demonstrate significant $\mathrm{T} 3$ binding to purified ANT or to the protein in its mitochondrial context (Rasmussen et al. 1989, Wrutniak et al. 1995).

However, the possibility that T3 by itself could induce this early influence is still under debate. First, after inhibiting deiodinations by propylthiouracil, Horst et al. (1989) reported that diiodothyronines (T2s), but not T3, induce this short-term mitochondrial influence. In addition, in agreement with the detection of $3^{\prime}, 5-\mathrm{T} 2$-binding sites in the organelle (Lanni et al. 1994, Leary et al. 1996), Goglia et al. (1994) found that 3',5-T2 binds to a subunit of cytochrome-c-oxidase, leading to a conformational change of the enzyme and an activation of the respiratory chain. Next, as mentioned previously for $\mathrm{T} 3$, inhibitors of protein synthesis do not alter the influence of T2 on the organelle (O'Reilly \& Murphy 1992). Yamaki et al. (1991) reported that $5^{\prime}$-deiodinase activity could be detected in mitochondria, thus suggesting that $\mathrm{T} 3$ to T2 conversion in the isolated organelle is not unlikely. Although controversial, this observation could explain the T3 influence recorded in this in vitro system. These data led to the proposition that $3^{\prime}, 5-\mathrm{T} 2$ is actually a mediator of the short-term thyroid hormone influence.

However, in our opinion, the detection of specific T3-binding sites in mitochondria by three separate teams (Sterling \& Milch 1975, Goglia et al. 1981, Hashizume \& Ichikawa 1982) does not allow us to exclude the possibility that T3 by itself is able to induce a part of the short-term hormonal influence. In particular, Sterling et al. (1984a) found that a $28 \mathrm{kDa}$ T3-binding protein was localized in the mitochondrial inner membrane. In agreement with this result, we have more recently identified a truncated form of the T3 nuclear receptor c-Erb A 1 displaying a similar molecular mass and the same localization in the organelle as Sterling's protein (p28) (Wrutniak et al. 1995). According to Bigler et al. (1992), p28 is synthesized by alternative translational initiation at an internal AUG in the messenger encoding the full-length nuclear receptor (Fig. 1). Now, we have evidence that this $\mathrm{T} 3$-binding protein is actively imported in isolated mitochondria ( $\mathrm{F}$ Casas, $\mathrm{C}$ WrutniakCabello \& G Cabello, unpublished observations). Although its exact function remains to be established, p28 could act as a receptor involved in the early mitochondrial T3 influence, taking into account its co-localization with components of the respiratory chain, uncoupling proteins (UCPs) or ANT.

\section{Delayed influence is probably induced at the nuclear level}

Studies were performed in order to identify the sites of action of T3 involved in delayed stimulation of oxygen consumption (Harper et al. 1993). In isolated mitochondria or in hepatocytes, they led to the conclusion that the proton leak across the inner membrane is an important target of thyroid hormone involved in its influence on oxygen consumption. In addition, studies performed in isolated mitochondria from hypothyroid rats suggested that reactions dissipating the protonmotive force like ATPase or ANT activity are also involved in this regulation, but these data were not confirmed in hyperthyroid mitochondria or in hepatocytes.

The proton leak represents about $20 \%$ of the multifactorial control of mitochondrial respiration (Brown 1992), and convergent data demonstrate that it is increased by thyroid hormone, according to several mechanisms. First, thyroid hormone increases the area of the inner membrane and alters its phospholipid composition (Brand et al. 1992, Bangur et al. 1995), leading to increased permeability to protons recorded 9-12 h after hormone administration (Horrum et al. 1992). More recently, the discovery of a family of mitochondrial UCPs (Ricquier \& Bouillaud 2000) provided another clue to explain this influence. In contrast to initial findings indicating that UCP1 expression was restricted to brown adipose tissue, it appears that almost all tissues express at least one member of the UCP family (UCP2, 3 and brain mitochondrial carrier protein-1). Interestingly, it is now established that UCP1 (Cassard-Doulcier et al. 1994, Guerra et al. 1996, Rabelo et al. 1996), UCP2 (Lanni et al. 1997) and UCP3 (Gong et al. 1997, Larkin et al. 1997) gene expression is increased by T3. In addition, Lanni et al. (1999) reported the existence of a substantial correlation between UCP3 mRNA levels, mitochondrial coupling and the thyroid state, thus suggesting that control of UCPs expression is involved in the $\mathrm{T} 3$ regulation of the proton leak. 

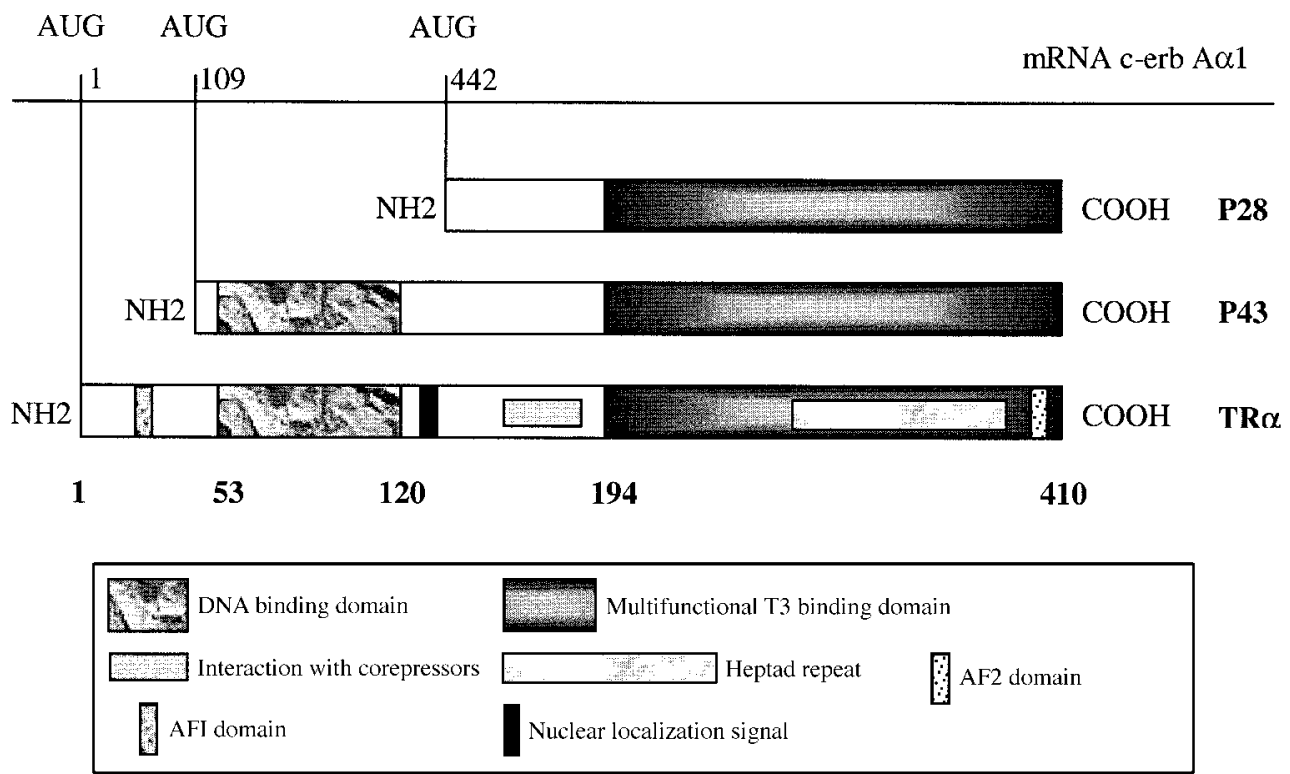

FIGURE 1. Two short c-Erb A 1 protein isoforms (p28 and p43) are synthesized by alternative translational initiation at internal AUG in the message encoding the full-length thyroid hormone receptor (Bigler et al. 1992). Whereas p28 is detected in the mitochondrial inner membrane, p43 is localized in the matrix of the organelle where it stimulates mitochondrial genome transcription in the presence of T3 (Wrutniak et al. 1995, Casas et al. 1999). TR 2 , T3 nuclear

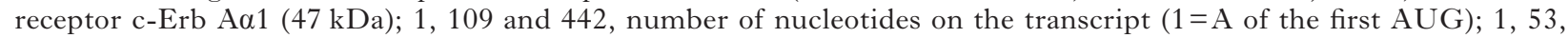
120, 194 and 410, number of amino acids on the c-Erb A $\alpha 1$ receptor.

Another finding of these studies is that thyroid hormone-induced changes in the phospholipid composition of the inner membrane include stimulation of cardiolipin synthase activity due to a rise in the mitochondrial phosphatidylglycerol pool (Hostetler 1991, Cao et al. 1995), thus increasing the amounts of cardiolipin (Paradies \& Ruggiero 1989, 1990). As cardiolipin stimulates several mitochondrial carriers and enzymes activities (Paradies \& Ruggiero 1989, 1990), this event could contribute to the delayed hormone influence on mitochondrial respiration.

Besides the proton leak, the influence of thyroid hormone on the processes involved in dissipation of the protonmotive force previously mentioned is in agreement with the observation that subunit $\beta \mathrm{F} 1$-ATPase of the mitochondrial complex synthesizing ATP (Izquierdo \& Cuezva 1993) and ANT (Dummler et al. 1996, Schonfeld et al. 1997) is encoded by genes whose expression is regulated by T3. As ATPase and AN'T activities contribute to the decrease in protonmotive force, these data suggest that direct or indirect induction of gene transcription is involved in delayed T3 influence.

Delayed influence of thyroid hormone on mitochondrial oxygen consumption, involving alter- ations in phospholipid synthesis, appeared clearly to be mainly initiated at the nuclear level. It remains to be established what is the contribution of direct mechanisms involving the c-Erb A nuclear receptors, and of indirect ones mediated by the induction of transcription factors responding to $\mathrm{T} 3$, such as nuclear respiratory factor 1 , whose $\mathrm{RE}$ has been identified in several nuclear respiratory genes (for review see Pillar \& Seitz 1997). However, recent data discussed below have raised the possibility that a direct mitochondrial pathway could also be involved in this delayed T3 influence.

\section{THYROID HORMONE INFLUENCE ON MITOCHONDRIAL GENOME EXPRESSION}

Besides its influence on oxygen consumption, numerous reports have established the influence of thyroid hormone on mitochondrial genome expression. Thyroid hormone administration in hypothyroid rats induces a 2 - to 8 -fold increase in liver mitochondrial mRNA levels (Mutvei et al. 1989b), and similar data have been reported in skeletal muscle with some tissue specificities (Wiesner et al. 1992). According to Mutvei et al. (1989b), this rise was accounted for by an elevated RNA synthesis. 
This conclusion is substantially supported by a recent observation indicating that $\mathrm{T} 3$ decreases mitochondrial mRNA half-life (Enriquez et al. 1999), thus ruling out the possibility that thyroid hormone could raise mitochondrial (mt) RNA levels by improving their stability.

This transcriptional influence has been explained by the finding that $\mathrm{T} 3$ increases mitochondrial transcription factor (mt-TFA) mRNA levels in rats (Garstka et al. 1994). As mt-TFA acts in mitochondria to stimulate mt-DNA replication and expression (Clayton 1991), this result suggested that the T3 transcriptional influence was essentially elicited at nuclear level. However, studies using isolated mitochondria from hypothyroid or control rat liver led to the conclusion that this mechanism was not exclusive. First, Martino et al. (1986) observed that in vitro addition of $\mathrm{T} 3$ stimulates mt-RNA polymerases in the absence of nuclear influence, with a latency period of less than $5 \mathrm{~min}$. Secondly, Enriquez et al. (1999) demonstrated that addition of minute amounts of the hormone to isolated mitochondria influenced mitochondrial transcription, and particularly the mRNA/rRNA ratio, in relation to changes in the pattern of protein binding to the mitochondrial genome. These data demonstrated that thyroid hormone influence on mitochondrial transcription involves direct action on the organelle transcription machinery.

In support of this result, we have previously identified, in the matrix of rat liver mitochondria, a second truncated form of the c-Erb A 1 nuclear receptor with a molecular mass of $43 \mathrm{kDa}(\mathrm{p} 43)$ (Wrutniak et al. 1995), synthesized by alternative translational initiation at another internal AUG in the messenger encoding the full-length nuclear receptor (Fig. 1). This protein, which, like p28, is not detected in the nucleus (Wrutniak et al. 1995), binds T3 with an affinity unsurprisingly similar to that reported for c-Erb A $\alpha 1$ (Casas et al. 1999). Moreover, in contrast to $\mathrm{p} 28$, this protein harbours the DNA-binding domain of the T3 nuclear receptor. Interestingly, gel shift experiments established that p43 efficiently bound to four sequences of the mitochondrial genome previously identified (Wrutniak et al. 1998, Casas et al. 1999), sharing strong homologies with T3 REs described on nuclear genes. Last, in organello transcription experiments demonstrated that p43 strongly increases mitochondrial genome transcription, and, as a consequence, mitochondrial protein synthesis (Casas et al. 1999). In agreement with Martino et al. (1986), this influence was detected as soon as the hormone had been present for 5 min. Complementary studies were performed in cultured cells. We found that $\mathrm{p} 43$ overexpression raises the level of mt-RNAs in a myoblast model in which mt-TFA is not a transcriptional T3 target (Casas et al. 1999). In addition, it stimulates cytochrome-c-oxidase activity and increases mitochondrial membrane potential assessed by rhodamine 123 uptake (Wrutniak et al. 1995). According to the short latency period recorded in our experiments, we suggest that this mechanism is in particular involved in the influence of T3 on mitochondrial oxygen consumption culminating in some hours, by increasing mitochondrial protein synthesis and consequently the activity of the respiratory chain as experimentally demonstrated (Wrutniak et al. 1995, Casas et al. 1999).

From a molecular point of view, we obtained indications that $\mathrm{p} 43$ monomer does not bind to mt-DNA (Casas et al. 1999), which led us to search for dimerization partners of this receptor. We recently found that $\mathrm{p} 43$ binds to one particular T3RE located in the mitochondrial D-loop by forming a complex with a $45 \mathrm{kDa}$ truncated form of another member of the nuclear receptor superfamily, PPAR $\gamma 2$ (peroxisome proliferator activated receptor), whose expression is induced by peroxisome proliferators (mt-PPAR) (Casas et al. $2000 a, b)$. Although devoid of any mitochondrial activity by itself, due to the absence of a ligand-binding domain (Casas et al. 2000a), co-expression of mt-PPAR with p43 significantly enhanced the stimulation of mitochondrial activity induced by $\mathrm{p} 43$ alone (F Casas, C Wrutniak-Cabello \& G Cabello, unpublished observations). These results provide an interesting explanation of the thyromimetic influence of fibrates reported in several studies (Hertz et al. 1991, Cai et al. 1996). In addition, they also suggest that $\mathrm{p} 43$ binds to the three other mitochondrial T3RE sequences by forming homodimerical or heterodimerical complexes with unidentified partners. Taken together, our data raise the possibility that other members of the nuclear receptor superfamily could be imported into the organelle. This hypothesis is already well supported by our data demonstrating that a particular c-Erb $\mathrm{A} \beta$ isoform $(\beta 0)$, expressed in non-mammalian species, is actively imported into mitochondria where it plays the same role as p43 (Casas et al. 1999), and by the finding that the glucocorticoid receptor is addressed into mitochondria (Scheller et al. 2000).

This possibility acutely raises the question of the process involved in the mitochondrial import of these receptors. We have not recorded putative mitochondrial localization signals in $\mathrm{p} 43$. However, we observed that deletion of the DNAbinding domain abrogates p43 import (F Casas, 
C Wrutniak-Cabello \& G Cabello, unpublished observations), thus emphasizing the importance of this well-conserved sequence among members of the nuclear receptor superfamily. In addition, studies of p28 import indicated that this receptor devoid of the DNA-binding domain is addressed into the organelle only in the presence of T3 $(\mathrm{F}$ Casas, C Wrutniak-Cabello \& G Cabello, unpublished observations). This last observation suggests that conformational changes consequent to T3 binding allow unmasking of a sequence inducing mitochondrial import. Overall, it appears that, at least for c-Erb A mitochondrial proteins, translocation in the organelle involves two domains with constitutive or T3-dependent activities. Besides their interest in endocrine regulation of mitochondrial activity, such studies could bring new original data concerning mitochondrial protein import.

As nuclear receptors exert their activity by interacting with transcriptional cofactors, other interesting questions are raised. In particular, the occurrence in the organelle of coactivators or corepressors has to be questioned. Today, no evidence has been provided that histone acetylation and deacetylation are important processes for mitochondrial genome transcription, according to the organization of the circular mt-DNA molecule. Therefore, it is unlikely that coactivators with histone acetylase activity, or interacting with histones acetylases, could play an important role in the regulation of mitochondrial transcription. Despite that, a search should be made for the presence of PPAR $\gamma$ coactivator, a common c-Erb A and PPAR $\gamma$ coactivator (Puigserver et al. 1998) interacting with steroid receptor coactivator histone acetylase (Puigserver et al. 1999), taking into account its involvement in the regulation of mitochondrial biogenesis ( $\mathrm{Wu}$ et al. 1999). However, a more systematic study of p43 interactions with known mitochondrial proteins, such as mt-TFA or mt-RNA polymerase, could bring interesting data.

Although numerous questions remains unsolved, these studies, which include the characterization of a new mitochondrial T3 receptor, have clearly established the existence of a T3 extra-nuclear pathway. As we have detected p43 in all tested vertebrate species (human, rat, mouse, rabbit, chicken, Xenopus), we suggest that this wellconserved pathway is of significant physiological importance. More generally, these results are of further interest; as a specific stimulation by $\mathrm{p} 43$ overexpression of the synthesis of enzyme subunits encoded by the mitochondrial genome is sufficient to induce stimulation of the organelle activity (Wrutniak et al. 1995), we suggest that the expression of subunits encoded by nuclear genes is not rate-limiting. This observation is consistent with previous data indicating the occurrence of an unassembled cytochrome-c-oxidase subunit pool in the cytosol of rat liver (Hundt et al. 1980). Similarly, in synchronous cultures of yeast, whereas nuclear-encoded cytochrome-c-oxidase subunits accumulate during the $\mathrm{G} 1$ and early $\mathrm{S}$ phases, they are integrated into the inner membrane in the late $\mathrm{S}$ phase only after the mitochondrially made subunits have accumulated (Somasundaram \& Jayaraman 1981), suggesting the latter could have rate-limiting importance for enzyme functioning. Moreover, it emphasizes the importance of the rapid regulation of mitochondrial transcription for organelle activity.

\section{THYROID HORMONE STIMULATES MITOCHONDRIOGENESIS}

Another well-established influence of thyroid hormone concerns the stimulation of mitochondriogenesis, considered as a long-term influence detected after a latency period much longer than $24 \mathrm{~h}$ (Gross 1971). Mitochondriogenesis is the result of numerous events leading to membrane phospholipid synthesis and assembly, DNA replication and stimulation of the expression of the mitochondrial genome and of nuclear genes encoding mitochondrial proteins. This apparent complexity is probably the reason for the length of the T3 latency period.

It is likely that T3 regulation of mitochondriogenesis involves both nuclear and mitochondrial receptors. As previously discussed, de novo lipid synthesis and mobilization in membranes probably result from the general influence of the hormone on lipid turnover assumed to be elicited at the nuclear level. Moreover, T3 stimulation of mt-TFA expression (Garstka et al. 1994) is probably a major mechanism involved in mitochondriogenesis as this factor stimulates mitochondrial genome expression and replication. The expression of several nuclear genes encoding mitochondrial proteins is T3regulated, as shown for $\beta$-F1ATPase, ANT, cytochrome c1, mt-TFA, UCPs and several sub-units of the respiratory chain (for review see Pillar \& Seitz 1997). In addition, improvement in the mitochondrial import of nuclear-encoded proteins has been observed in cardiac muscle cells (Craig et al. 1998), in agreement with the study of Schneider \& Hood (2000) indicating that mt-heat shock protein 70 expression, a chaperone involved in import, is increased by thyroid hormone. However, the work of Alvarez-Dolado et al. (1999), reporting that expression of mitochondrial 
preprotein translocase of outer membrane 70 , a component of the organelle import apparatus encoded by a nuclear gene, is negatively regulated by $\mathrm{T} 3$ in several regions of the brain, points to the existence of differential regulation depending on the relevant tissue. Lastly, at the mitochondrial level, by activating p43 the hormone directly increases mitochondrial genome transcription and synthesis of the corresponding proteins (Casas et al. 1999).

Therefore, it appears that mitochondriogenesis needs some coordination between nuclear and mitochondrial genome expression. Interestingly, the c-erb A $\alpha$ gene simultaneously encodes a nuclear and a mitochondrial T3 receptor, thus providing an efficient system to coordinate expression of a number of nuclear genes encoding mitochondrial proteins, and expression of the mitochondrial genome (Casas et al. 1999). This dual influence not only explains the major role of $\mathrm{T} 3$ in the regulation of mitochondriogenesis, but also underlines the complementarities between the nuclear and direct mitochondrial T3 pathways. As other members of the nuclear receptor superfamily have been characterized in the organelle (PPAR, glucocorticoid receptor), it is likely that they could also contribute to this coordination, thus ensuring fine regulation of mitochondriogenesis in response to physiological stimuli.

\section{PHYSIOLOGICAL IMPORTANCE OF THE DIRECT MITOCHONDRIAL T3 PATHWAY}

In this review, it clearly appears that a direct $\mathrm{T} 3$ mitochondrial pathway does indeed exist, mediated by at least one receptor encoded by the c-erb $\mathrm{A} \alpha$ gene. As p43 is the first T3 receptor identified at the origin of an extra-nuclear action of thyroid hormone, this raises the question of the exact physiological importance of this new hormonal pathway.

T3 influence at the mitochondrial level initially suggested that the pathway was essentially involved in the regulation of fuel metabolism and thermogenesis. This possibility is consistent with the observation that $\mathrm{p} 43$ overexpression induces stimulation of mitochondrial activity (Wrutniak et al. 1995). In addition, whereas high amounts of this receptor are present in mitochondria from brown adipose tissue implicated in non-shivering thermogenesis, p43 is not detected in brain organelles, a tissue considered as not responsible for the calorigenic influence of thyroid hormone (Wrutniak et al. 1995, Casas et al. 2000a). These data argue in favour of an involvement of this pathway in T3

www.endocrinology.org thermogenic effects. This possibility agrees well with the observation that body temperature is specifically altered by disruption of the c-erb $\mathrm{A} \alpha$ gene, encoding a nuclear and a mitochondrial receptor, whereas knock-out of the c-erb $A \beta$ gene only encoding nuclear T3 receptors is without influence (Wikstrom et al. 1998, Johansson et al. 1999).

However, the importance of mitochondrial activity in other important physiological processes is currently emerging. The organelle function in particular seems strongly implicated in the processes of development. First, mitochondria play a key role in the induction of apoptosis (for review see Loeffler \& Kroemer 2000). In addition, several studies have established that inhibition of mitochondrial activity, either by deleting mt-DNA $\left(\mathrm{Rho}^{0}\right.$ cells) or by blocking translation in the organelle, stops or decreases proliferation of different cell lines (Leblond-Larouche et al. 1979, Morais et al. 1980, Van den Bogert et al. 1992). Furthermore, the general activity of the organelle, not restricted to energy production, is implicated in such regulation (Grégoire et al. 1984, Buchet \& Godinot 1998). Lastly, mitochondrial protein synthesis inhibition is associated with the impairment of differentiation in different cell types, such as mouse erythroleukaemia (Kaneko et al. 1988) and mastocytoma cells (Laeng et al. 1988), neurons (Vayssière et al. 1992), and human (Herzberg et al. 1993), avian (Korohoda et al. 1993) or murine myoblasts (Hamai et al. 1997). In agreement with this set of data, mt-TFA gene knock-out in mice is associated with embryonic lethality (Larsson et al. 1998). Despite these reports, it was not clear if these adverse influences were a non-specific consequence of impairment in cell viability due to insufficient ATP stores, or attested to the occurrence of an actual physiological regulation of cell proliferation and differentiation by the organelle activity.

To clarify this point, we studied the influence of the direct mitochondrial T3 pathway on myoblast differentiation (Rochard et al. 2000). First, T3 is a major regulator of myoblast differentiation (Marchal et al. 1993), through mechanisms involving its c-Erb A nuclear receptors (Cassar-Malek et al. 1996, Marchal et al. 1996). Secondly, the molecular events inducing terminal differentiation in this cell type are relatively well known, with a major influence of myogenic factors acting as muscle-specific transcription factors (Myf 5, MyoD, myogenin and MRF4). Gene knock-out in mice provided evidence that Myf 5 and MyoD are more involved in the acquisition of the muscle phenotype, whereas myogenin is involved in terminal differentiation by inducing myoblast fusion and expression 
of muscle-specific proteins. In addition, overexpression of only one of these transcription factors in cells other than myoblasts can induce expression of a myogenic phenotype.

We first observed that $\mathrm{p} 43$ overexpression increases myoblast withdrawal from the cell cycle, an important step in myogenic differentiation, and stimulates their differentiation. In contrast, chloramphenicol, a drug inducing the opposite influence to $\mathrm{p} 43$ by reducing mitochondrial protein synthesis, inhibits myoblast withdrawal from the cell cycle and their differentiation. In this study (Rochard et al. 2000), we obtained good evidence that changes in ATP production were not involved in this myogenic influence. More interestingly, we found that myogenin expression was increased by $\mathrm{p} 43$ overexpression and decreased by chloramphenicol, events elicited at transcriptional level, thus establishing the existence of an actual regulation of myoblast differentiation by mitochondrial activity. The signalling at the origin of the influence of the organelle on nuclear gene expression remains to be identified, but recent data already suggest that calcium signalling is probably involved (Luo et al. 1997, Biswas et al. 1999). We also observed that the ability of myogenic factors to induce terminal differentiation was under the control of mitochondrial activity.

These data shed new light on the sharp increase in mitochondrial activity spontaneously occurring just before myoblast differentiation, already proposed as a possible mechanism involved in the commitment of these cells in the differentiation programme (Rochard et al. 1996). As we have recently observed a similar regulation of preadipocyte differentiation (A Fraysse, C WrutniakCabello, L Daury, A Rodier, F Casas, P Rochard, G Cabello \& J Charrier, unpublished observations), this set of data demonstrates that, like the nuclear pathway, the direct mitochondrial T3 pathway is involved in the regulation of cell differentiation.

\section{CONCLUSIONS}

In this review, we have stressed that the complex regulation of mitochondrial activity by thyroid hormone involves several pathways. Besides the well-established nuclear pathway involving the c-Erb A receptors, it appears that a recently identified direct mitochondrial pathway also plays a significant role by stimulating mitochondrial genome transcription with a very short latency period. Interestingly, both mechanisms could contribute to setting up efficient coordination in the induction of transcription of the mitochondrial genome and of nuclear genes encoding mitochondrial proteins needed for mitochondriogenesis. Moreover, it appears that by its short-term action, T3 and/or T2 could immediately adapt mitochondrial activity to abrupt changes in environmental conditions, whereas when acting through $\mathrm{p} 43$, T3 rapidly increases the efficiency of the mitochondrial apparatus to respond to these changes within minutes. In association with more delayed responses through the nuclear pathway leading to a stimulation of mitochondriogenesis, these mechanisms provide an efficient mitochondrial response to abrupt and/or prolonged changes in physiological conditions.

Lastly, it also appears that, like the nuclear T3 pathway, the direct mitochondrial pathway is deeply involved in the regulation of cell differentiation, further underlining the complementarities of these mechanisms initiated at different levels. In addition, we would emphasize that thyroid hormone regulation of mitochondrial activity, simultaneously influencing ATP production and cell differentiation, an energy-expensive process, could be a major link between metabolism and development. All these considerations led us to the conviction that studies on mitochondrial $\mathrm{T} 3$ regulation will shed new light on major interactions between endocrinology, metabolism and development.

\section{REFERENCES}

Abel ED, Boers ME, Pazos-Moura C, Moura E, Kaulbach H, Zakaria M, Lowell B, Radovick S, Liberman MC \& Wondisford F 1999 Divergent roles for thyroid hormone receptor beta isoforms in the endocrine axis and the auditory system. Fournal of Clinical Investigation 104 291-300.

Alvarez-Dolado M, Gonzalez-Moreno M, Valencia A, Zenke M, Bernal J \& Munoz A 1999 Identification of mammalian homologue of the fungal Tom70 mitochondrial precursor protein import receptor as a thyroid hormone-regulated gene in specific brain regions. Fournal of Neurochemistry $\mathbf{7 3}$ 2240-2249.

Andrews JF, Lynch M \& Moore RE 1979 The early metabolic response of lambs to small doses of 3,3',5-triiodothyronine. Fournal of Physiology 293 49P.

Bangur CS, Holland JL \& Katyare SS 1995 Thyroid hormone treatment alters phospholipid composition and membrane fluidity of rat brain mitochondria. Biochemical Fournal 305 29-32.

Bigler J, Hokanson W \& Eisenman RN 1992 Thyroid hormone receptor transcriptional activity is potentially autoregulated by truncated forms of the receptor. Molecular and Cellular Biology 12 2406-2417.

Biswas G, Adebanjo OA, Freedman BD, Anandatheerthavarada HK, Vijayasarathy C, Zaidi N, Kotlikoff M \& Avadhani NG 1999 Retrograde $\mathrm{Ca}^{2+}$ signaling in C2C12 skeletal myocytes in response to mitochondrial genetic and metabolic stress: a novel mode of interorganelle crosstalk. EMBO Fournal 18 522-533. 
Bodenner DL, Mroczynski MA, Weintraub BD, Radovick S \& Wondisford FE 1991 A detailed functional and structural analysis of a major thyroid hormone inhibitory element in the human thyrotropin beta-subunit gene. Fournal of Biological Chemistry 266 21666-21673.

Brand MD \& Murphy MP 1987 Control of electron flux through the respiratory chain in mitochondria and cells. Biological Review of the Cambridge Philosophical Society $\mathbf{6 2}$ 141-193.

Brand MD, Steverding D, Kadenbach B, Stevenson PM \& Hafner RP 1992 The mechanism of the increase in mitochondrial proton permeability induced by thyroid hormones. European Fournal of Biochemistry 206 $775-781$

Brown GC 1992 Control of respiration and ATP synthesis in mammalian mitochondria and cells. Biochemical Fournal 284 $1-13$.

Buchet K \& Godinot C 1998 Functional F1-ATPase essential in maintaining growth and membrane potential of human mitochondrial DNA-depleted Rho degrees cells. Fournal of Biological Chemistry 273 22983-22989.

Burnside J, Darling DS, Carr FE \& Chin WW 1989 Thyroid hormone regulation of the rat glycoprotein hormone alpha-subunit gene promoter activity. Fournal of Biological Chemistry 264 6886-6891.

Cai Y, Nelson BD, Li R, Luciakova K \& DePierre JW 1996 Thyromimetic action of the peroxisome proliferators clofibrate, perfluorooctanoic acid, and acetylsalicylic acid includes changes in mRNA levels for certain genes involved in mitochondrial biogenesis. Archives of Biochemistry and Biophysics 325 107-112.

Cao SG, Cheng P, Angel A \& Hatch GM 1995 Thyroxine stimulates phosphatidylglycerolphosphate synthase activity in rat heart mitochondria. Biochimica et Biophysica Acta 1256 241-244.

Casas F, Rochard P, Rodier A, Cassar-Malek I, MarchalVictorion S, Wiesner RJ, Cabello G \& Wrutniak C 1999 A variant form of the nuclear triiodothyronine receptor $\mathrm{c}-\mathrm{Erb}$ A $\alpha 1$ plays a direct role in regulation of mitochondrial RNA synthesis. Molecular and Cellular Biology 19 7913-7924.

Casas F, Domenjoud L, Rochard P, Hatier R, Rodier A, Daury L, Bianchi A, Kremarik-Bouillaud P, Becuwe P, Keller JM, Schohn H, Wrutniak-Cabello C, Cabello G \& Dauça M $2000 a$ A $45 \mathrm{kDa}$ protein related to PPAR $\gamma 2$, induced by peroxisome proliferators, is located in the mitochondrial matrix. FEBS Letters 478 4-8.

Casas F, Pineau T, Rochard P, Rodier A, Daury L, Dauça M, Cabello G \& Wrutniak-Cabello C $2000 b$ New molecular aspects of regulation of mitochondrial activity by fenofibrate and fasting. FEBS Letters 482 71-74.

Cassard-Doulcier AM, Larose M, Matamala JC, Champigny $\mathrm{O}$, Bouillaud F \& Ricquier D 1994 In vitro interactions between nuclear proteins and uncoupling protein gene promoter reveal several putative transactivating factors including Ets1, retinoid X receptor, thyroid hormone receptor, and a CACCC box-binding protein. Fournal of Biological Chemistry 269 24335-24342.

Cassar-Malek I, Marchal S, Rochard P, Casas F, Wrutniak C, Samarut J \& Cabello G 1996 Induction of c-Erb A-AP-1 interactions and c-Erb A transcriptional activity in myoblasts by RXR. Consequences for muscle differentiation. Fournal of Biological Chemistry 271 11392-11399.

Chassande O, Fraichard A, Gauthier K, Flamant F, Legrand C, Savatier P, Laudet V \& Samarut J 1997 Identification of transcripts initiated from an internal promoter in the c-erbA alpha locus that encode inhibitors of retinoic acid receptoralpha and triiodothyronine receptor activities. Molecular Endocrinology 11 1278-1290.
Clayton DA 1991 Replication and transcription of vertebrate mitochondrial DNA. Annual Review of Cell Biology 7 453-478.

Craig E, Chesley A \& Hood D 1998 Thyroid hormone modifies mitochondrial phenotype by increasing protein import without altering degradation. American Fournal of Physiology 275 1508-1515.

Davis PJ, Davis FB \& Lawrence WB 1989 Thyroid hormone regulation of membrane $\mathrm{Ca}(2+)$-ATPase activity. Endocrine Research 15 651-682.

Dummler K, Muller S \& Seitz HJ 1996 Regulation of adenine nucleotide translocase and glycerol 3-phosphate dehydrogenase expression by thyroid hormones in different rat tissues. Biochemical Fournal 317 913-918.

Enriquez JA, Fernandez-Silva P, Garrido-Perez N, Lopez-Perez MJ, Perez-Martos A \& Montoya J 1999 Direct regulation of mitochondrial RNA synthesis by thyroid hormone. Molecular and Cellular Biology 19 $657-670$.

Forrest D, Hanebuth E, Smeyne RJ, Everds N, Stewart CL, Wehner JM \& Curran T 1996 Recessive resistance to thyroid hormone in mice lacking thyroid hormone receptor $\beta$ : evidence for tissue-specific modulation of receptor function. EMBO Fournal 15 3006-3015.

Garstka HL, Fäcke M, Escribano JR \& Wiesner RJ 1994 Stoichiometry of mitochondrial transcripts and regulation of gene expression by mitochondrial transcription factor A. Biochemical and Biophysical Research Communications 200 619-626.

Gauthier K, Chassande O, Plateroti M, Roux JP, Legrand C, Pain B, Rousset B, Weiss R, Trouillas J \& Samarut J 1999 Different functions for the thyroid hormone receptors TRalpha and TRbeta in the control of thyroid hormone production and post-natal development. EMBO Fournal 18 623-631.

Goglia F, Torresani J, Bugli P, Barletta A \& Liverini G 1981 In vitro binding of triiodothyronine to rat liver mitochondria. Pflügers Archiv 390 120-124.

Goglia F, Lanni A, Barth J \& Kadenbach B 1994 Interaction of diiodothyronines with isolated cytochrome c oxidase. FEBS Letters 346 295-298.

Gong DW, He Y, Karas M \& Reitman M 1997 Uncoupling protein-3 is a mediator of thermogenesis modulated by thyroid hormone, $\beta 3$-adrenergic agonists, and leptin. Fournal of Biological Chemistry 272 24129-24132.

Grégoire M, Morais R, Quilliam MA \& Gravel D 1984 On auxotrophy for pyrimidines of respiration deficient chick embryo cells. European Fournal of Biochemistry 142 49-55.

Gross NJ 1971 Control of mitochondrial turnover under the influence of thyroid hormone. Fournal of Cell Biology $\mathbf{4 8}$ $29-40$.

Guerra C, Ronsero C, Porras A, Fernandez M \& Benito M 1996 Triiodothyronine induces the transcription of the uncoupling protein gene and stabilizes its mRNA in fetal rat brown adipocyte primary cultures. Fournal of Biological Chemistry 271 2076-2081.

Hamai N, Nakamura M \& Asano A 1997 Inhibition of mitochondrial protein synthesis impaired $\mathrm{C} 2 \mathrm{C} 12$ myoblast differentiation. Cell Structure and Function 22 421-431.

Harper ME, Ballantyne JS, Leach M \& Brand MD 1993 Effects of thyroid hormones on oxidative phosphorylation. Biochemical Society Transactions 21 785-792.

Hashizume K \& Ichikawa K 1982 Localization of 3,5,3'triiodothyronine receptor in rat mitochondrial membrane. Biochemical and Biophysical Research Communications 106 920-926.

Hashizume K, Kobayashi M, Miyamoto T \& Yamauchi K 1986 Dependence of the mitochondrial uptake of 
tri-iodothyronine (T3) in rat kidney on cytosolic T3-binding protein. Endocrinology 119 1063-1070.

Hertz R, Aurbach R, Hashimato T \& Bar-Tana J 1991

Thyromimetic effect of peroxisomal proliferators in rat liver. Biochemical Fournal 274 745-751.

Herzberg NH, Middlekoop E, Adorf M, Dekker HL, Van Galen MJ, Van den Berg M, Bolhuis PA \& Van den Bogert C 1993 Mitochondria in cultured human muscle cells depleted of mitochondrial DNA. European Fournal of Cell Biology 61 400-408.

Hoch FL 1988 Lipids and thyroid hormones. Progress in Lipid Research 27 199-270.

Horrum MA, Tobin RB \& Ecklund RE 1992 The early triiodothyronine-induced changes in state IV respiration is not regulated by the proton permeability of the mitochondrial inner membrane. Biochemistry International 28 813-821.

Horst C, Rokos H \& Seitz HJ 1989 Rapid stimulation of hepatic oxygen consumption by 3,5-di-iodo-L-thyronine. Biochemical fournal 261 945-950.

Hostetler KY 1991 Effect of thyroxine on the activity of mitochondrial cardiolipin synthase in rat liver. Biochimica et Biophysica Acta 1086 139-140.

Hundt EM, Trapp M \& Kadenbach B 1980 Biosynthesis of cytochrome c oxidase in isolated rat hepatocytes. FEBS Letters 115 95-99.

Izquierdo JM \& Cuezva J 1993 Thyroid hormones promote transcriptional activation of the nuclear gene coding for mitochondrial $\beta$-F1-ATPase in rat liver. FEBS Letters 323 109-112.

Johansson C, Gothe S, Forrest D, Vennstrom B \& Thoren P 1999 Cardiovascular phenotype and temperature control in mice lacking thyroid hormone receptor-beta or both alpha1 and beta. American Fournal of Physiology 276 H2006-H2012.

Kaneko T, Watanabe T \& Oishi M 1988 Effects of mitochondrial protein synthesis inhibitors on erythroid differentiation of mouse erythroleukemia (Friend) cells. Molecular and Cellular Biology 8 3311-3315.

Korohoda W, Pietrzkowski Z \& Reiss K 1993

Chloramphenicol, an inhibitor of mitochondrial protein synthesis, inhibits myoblast fusion and myotube differentiation. Folia Histochemica et Cytobiologica 31 9-13.

Laeng H, Schneider E, Bolli R, Zimmermann A, Schaffner T \& Schindler R 1988 Participation of mitochondrial proliferation in morphological differentiation of murine mastocytoma cells. Experimental Cell Research 179 222-232.

Lanni A, Moreno M, Horst C, Lombardi A \& Goglia F 1994 Specific binding sites for $3,3^{\prime}$-diiodo-L-thyronine $\left(3,3^{\prime}-\mathrm{T} 2\right)$ in rat liver mitochondria. FEBS Letters 351 237-240.

Lanni A, De Felice M, Lombardi A, Moreno M, Fleury C, Ricquier D \& Goglia F 1997 Induction of UCP 2 mRNA by thyroid hormones in rat heart. FEBS Letters 418 171-174.

Lanni A, Beneduce L, Lombardi A, Moreno M, Boss O, Muzzin P, Giacobino JP \& Goglia F 1999 Expression of uncoupling protein- 3 and mitochondrial activity in the transition from hypothyroid to hyperthyroid state in rat skeletal muscle. FEBS Letters 444 250-254.

Larkin S, Mull E, Miao W, Pittner R, Albrandt K, Moore C, Young A, Denaro M \& Beaumont K 1997 Regulation of a third member of the uncoupling protein family, UCP3, by cold and thyroid hormone. Biochemical and Biophysical Research Communications 240 222-227.

Larsson NG, Wang J, Wilhelmsson H, Oldfors A, Rustin P, Lewandoski M, Barsh GS \& Clayton DA 1998 Mitochondrial transcription factor A is necessary for mtDNA maintenance and embryogenesis in mice. Nature Genetics 18 231-236.
Leary SC, Barton KN \& Ballantyne JS 1996 Thyroid effects of 3,5,3'-triiodothyronine and 3,5-diiodothyronine on mitochondrial metabolism in the goldfish Carassius auratus. General and Comparative Endocrinology 104 61-66.

Leblond-Larouche L, Morais R \& Zollinger M 1979 Studies of the effect of chloramphenicol, ethidium bromide and camptothecin on the reproduction of Rous sarcoma virus in infected chick embryo cells. Fournal of General Virology 44 323-331.

Loeffler M \& Kroemer G 2000 The mitochondrion in cell death control: certainties and incognita. Experimental Cell Research 256 19-26.

Luo Y, Bond JD \& Ingram VM 1997 Compromised mitochondrial function leads to increased cytosolic calcium and to activation of MAP kinases. PNAS 94 9705-9710.

Lynch MA, Andrews JF \& Moore RE 1985 Low doses of T3 induce a rapid metabolic response in young lambs. Hormones and Metabolism 17 63-66.

Marchal S, Cassar-Malek I, Pons F, Wrutniak C \& Cabello G 1993 Triiodothyronine influences quail myoblast proliferation and differentiation. Biology of the Cell $\mathbf{7 8}$ 191-197.

Marchal S, Cassar-Malek I, Rodier A, Wrutniak C \& Cabello G 1996 Mécanismes moléculaires impliqués dans l'activité myogénique de la triiodothyronine (T3). Médecine/Sciences 12 1065-1076.

Martino G, Covello C, De Giovanni R, Filipelli R \& Pitrelli 1986 Direct in vitro action of thyroid hormones on mitochondrial RNA-polymerase. Molecular Biology Reports $11205-211$.

Morais R, Grégoire M, Jeannotte L \& Gravel D 1980 Chick embryo cells rendered respiration-deficient by chloramphenicol and ethidium bromide are auxotrophic for pyrimidines. Biochemical and Biophysical Research Communications 94 71-77.

Morel G, Ricard-Blum S \& Ardail D 1996 Kinetics of internalization and subcellular binding sites for $\mathrm{T} 3$ in mouse liver. Biology of the Cell 86 167-174.

Mutvei A, Husman B, Andersson G \& Nelson BD 1989a Thyroid hormone and not growth hormone is the principal regulator of mammalian mitochondrial biogenesis. Acta Endocrinologica 121 223-228.

Mutvei A, Kuzela S \& Nelson BD $1989 b$ Control of mitochondrial transcription by thyroid hormone. European Fournal of Biochemistry 180 235-240.

Nobes CD, Brown GC, Olive PN \& Brand MD 1990 Non-ohmic proton conductance of the mitochondrial inner membrane in hepatocytes. Fournal of Biological Chemistry 265 12903-12909.

O'Reilly I \& Murphy MP 1992 Treatment of hypothyroid rats with T2 (3,5-di-iodo-L-thyronine) rapidly stimulates respiration in subsequently isolated mitochondria. Biochemical Society Transactions 20 59S.

Palacios-Romero R \& Mowbray J 1979 Evidence for the rapid direct control both in vivo and in vitro of the efficiency of oxidative phosphorylation by $3,5,3^{\prime}$-tri-iodo-L-thyronine in rats. Biochemical Fournal 184 527-538.

Paradies G \& Ruggiero FM 1989 Decreased activity of pyruvate translocator and changes in the lipid composition in heart mitochondria from hypothyroid rats. Archives of Biochemistry and Biophysics 269 595-602.

Paradies G \& Ruggiero FM 1990 Stimulation of phosphate transport in rat-liver mitochondria by thyroid hormones. Biochimica et Biophysica Acta 1019 133-136.

Pillar TM \& Seitz HJ 1997 Thyroid hormone and gene expression in the regulation of mitochondrial respiratory function. European Fournal of Endocrinology 136 $231-239$ 
Puigserver P, Wu Z, Park CW, Graves R, Wright M \& Spiegelman BM 1998 A cold-inducible coactivator of nuclear receptors linked to adaptative thermogenesis. Cell $\mathbf{9 2}$ 829-839.

Puigserver P, Adelmant G, Wu Z, Fan M, Xu J, O'Malley B \& Spiegelman BM 1999 Activation of PPAR $\gamma$ coactivator-1 through transcription factor docking. Science $\mathbf{2 8 6}$ 1368-1371.

Rabelo R, Reyes C, Schifman A \& Silva JE 1996 Interactions among receptors, thyroid hormone response elements and ligands in the regulation of the rat uncoupling protein gene expression by thyroid hormone. Endocrinology 137 3478-3487.

Rasmussen UB, Köherle J, Rokos H \& Hesch RD 1989 Thyroid hormone effect on rat heart mitochondrial proteins and affinity labeling with N-bromoacetyl-3,3',5-triiodo-Lthyronine. Lack of direct effect on the adenine nucleotide translocase. FEBS Letters 255 385-390.

Ricquier D \& Bouillaud F 2000 Uncoupling protein homologues: UCP1, UCP2, UCP3, StUCP and AtUCP. Biochemical fournal 345 161-179.

Rochard P, Cassar-Malek I, Marchal S, Wrutniak C \& Cabello G 1996 Changes in mitochondrial activity during avian myoblast differentiation: influence of triiodothyronine or $\mathrm{v}$-Erb A expression. Fournal of Cellular Physiology 168 239-247.

Rochard P, Rodier A, Casas F, Cassar-Malek I, Marchal-Victorion S, Daury L, Wrutniak C \& Cabello G 2000 Mitochondrial activity is involved in the regulation of myoblast differentiation through myogenin expression and activity of myogenic factors. Fournal of Biological Chemistry 275 2733-2744.

Scheller K, Sekeris CE, Krohne G, Hock R, Hansen IA \& Scheer U 2000 Localization of glucocorticoid hormone receptors in mitochondria of human cells. European Fournal of Cell Biology 79 299-307.

Schneider JJ \& Hood DA 2000 Effect of thyroid hormone on mtHSP 70 expression, mitochondrial import and processing in cardiac muscle. Fournal of Endocrinology 165 9-17.

Schonfeld P, Wieckowski MR \& Wojtczak L 1997 Thyroid hormone-induced expression of the ADP/ATP carrier and its effect on fatty acid-induced uncoupling of oxidative phosphorylation. FEBS Letters 416 19-22.

Segal J 1989 Action of the thyroid hormone at the level of the plasma membrane. Endocrine Research 15 619-649.

Somasundaram T \& Jayaraman J 1981 Synthesis and assembly of cytochrome c oxidase in synchronous cultures of yeast. Biochemistry 20 5369-5373.

Sterling K 1986 Direct thyroid hormone activation of mitochondria: the role of adenine nucleotide translocase. Endocrinology 119 292-295.

Sterling K \& Brenner MA 1995 Thyroid hormone action: effect of triiodothyronine on mitochondrial adenine nucleotide translocase in vivo and in vitro. Metabolism 34 193-199.

Sterling K \& Milch PO 1975 Thyroid hormone binding by a component of mitochondrial membrane. PNAS 72 3225-3229.

Sterling K, Milch PO, Brenner MA \& Lazarus JH 1977

Thyroid hormone action: the mitochondrial pathway. Science 197 996-999.
Sterling K, Brenner MA \& Sakurada T 1980 Rapid effect of triiodothyronine on the mitochondrial pathway in rat liver in vivo. Science 210 340-343.

Sterling K, Campbell GA \& Brenner MA $1984 a$ Purification of the mitochondrial triiodothyronine (T3) receptor from rat liver. Acta Endocrinologica 105 391-397.

Sterling K, Campbell GA, Taliadouros GS \& Nunez EA $1984 b$ Mitochondrial binding of triiodothyronine (T3).

Demonstration by electron-microscopic radioautography of dispersed liver cells. Cell and Tissue Research 236 321-325.

Thomas WE, Crespo-Armas A \& Mowbray J 1987 The influence of nanomolar calcium ions and physiological levels of thyroid hormone on oxidative phosphorylation in rat liver mitochondria. A possible signal amplification control mechanism. Biochemical fournal 247 315-320.

Van den Bogert C, Spelbrink JN \& Dekker HL 1992 Relationship between culture conditions and the dependency on mitochondrial function of mammalian cell proliferation. Fournal of Cellular Physiology 152 632-638.

Vayssière JL, Cordeau-Lossouarn L, Larcher JC, Basseville M, Gros F \& Croizat B 1992 Participation of the mitochondrial genome in the differentiation of neuroblastoma cells. In Vitro Cellular and Developmental Biology 28 763-772.

Wiesner RJ, Kurowski TT \& Zak R 1992 Regulation by thyroid hormone of nuclear and mitochondrial genes encoding subunits of cytochrome-c oxidase in rat liver and skeletal muscle. Molecular Endocrinology 6 1458-1467.

Wikstrom L, Johansson C, Salto C, Barlow C, Campos Barros A, Baas F, Forrest D, Thoren P \& Vennstrom B 1998 Abnormal heart rate and body temperature in mice lacking thyroid hormone receptor alpha 1. EMBO Fournal 17 455-461.

Wrutniak C \& Cabello G 1986 Influence of hypothyroidism on the lipolytic activity of norepinephrine in the newborn lamb. Fournal of Endocrinology 108 451-454.

Wrutniak C, Cassar-Malek I, Marchal S, Rascle A, Heusser S, Keller JM, Fléchon J, Dauça M, Samarut J, Ghysdael J \& Cabello G 1995 A $43 \mathrm{kDa}$ protein related to c-Erb A $\alpha 1$ is located in the mitochondrial matrix of rat liver. Fournal of Biological Chemistry 270 16347-16354.

Wrutniak C, Rochard P, Casas F, Fraysse A, Charrier J \& Cabello G 1998 Physiological importance of the T3 mitochondrial pathway. Annals of the New York Academy of Sciences 839 93-100.

Wu Z, Puigserver P, Andersson U, Zhang C, Adelmant G, Mootha V, Troy A, Cinti S, Lowell B, Scarpulla RC \& Spiegelman BM 1999 Mechanisms controlling mitochondrial biogenesis and respiration through the thermogenesis coactivator PGC-1. Cell 98 115-124.

Yamaki M, Murayama N, Yoshida K, Kusano E, Sakurada T \& Asano Y 1991 Subcellular distribution of thyroxine 5 -monodeiodinase activity in rabbit kidney. Hormone and Metabolism Research 23 7-11.

REVISED MANUSCRIPT RECEIVED 2 October 2000 